
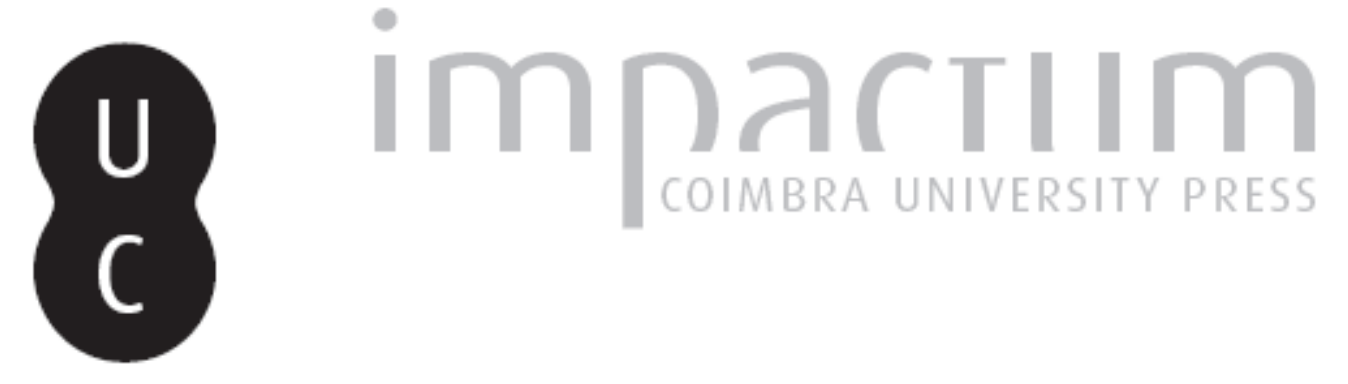

\title{
A cultura do trigo e a degradação dos solos na margem esquerda do Guadiana
}

Autor(es): Roxo, Maria José

Publicado por: Associação Portuguesa de Riscos, Prevenção e Segurança

URL persistente:

URI:http://hdl.handle.net/10316.2/40110

DOI:

DOI:https://doi.org/10.14195/1647-7723_7_3

Accessed : $\quad$ 26-Apr-2023 02:14:46

A navegação consulta e descarregamento dos títulos inseridos nas Bibliotecas Digitais UC Digitalis, UC Pombalina e UC Impactum, pressupõem a aceitação plena e sem reservas dos Termos e Condições de Uso destas Bibliotecas Digitais, disponíveis em https://digitalis.uc.pt/pt-pt/termos.

Conforme exposto nos referidos Termos e Condições de Uso, o descarregamento de títulos de acesso restrito requer uma licença válida de autorização devendo o utilizador aceder ao(s) documento(s) a partir de um endereço de IP da instituição detentora da supramencionada licença.

Ao utilizador é apenas permitido o descarregamento para uso pessoal, pelo que o emprego do(s) título(s) descarregado(s) para outro fim, designadamente comercial, carece de autorização do respetivo autor ou editor da obra.

Na medida em que todas as obras da UC Digitalis se encontram protegidas pelo Código do Direito de Autor e Direitos Conexos e demais legislação aplicável, toda a cópia, parcial ou total, deste documento, nos casos em que é legalmente admitida, deverá conter ou fazer-se acompanhar por este aviso.

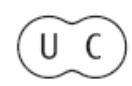




\title{
A Cultura do Trigo e a Degradação dos Solos na Margem Esquerda do Guadiana
}

\author{
Maria José Roxo*
}

\section{Resumo:}

A cultura de cereais de Inverno, em particular a do trigo, foi e continua a ser uma das actividades agrícolas que mais contribuem para a degradação dos solos na margem esquerda do rio Guadiana. Desde há vários séculos que esta área tem sido utilizada para a cultura cerealifera ao longo de um processo de intensificação e incremento agrícola.

O trigo é aí uma cultura degradante dos recursos naturais, pois contribui para o aumento da degradação dos solos e dos ecossistemas, assim como para o processo de desertificação. É fundamental incentivar a implementação das actuais medidas agro-ambientais com objectivos de conservação do solo, da vegetação arbustiva e da floresta de quercíneas, assim como dar maiores incentivos para novos usos agrícolas e não agrícolas que contribuam para a protecção do solo e da água como recursos naturais essenciais e para a qualidade do ambiente e da paisagem.

Palavras chave:

Degradação do solo, erosão hídrica, trigo, desertificação, Alentejo.

Résumé:

La culture des céréales d'hiver, en particulier celle du blé, a été et continue àêtre une des activités agricoles les plus importantes pour la dégradation des sols dans la rive gauche du fleuve Guadiana. Depuis longtemps cette région est occupée par la céréaliculture tout au long d'un processus d'intensification et modernisation agricole.

Le blé est là une culture dégradante des ressources naturelles. Il contribue pour l'augmentation de la dégradation des sols et des écossystèmes, ainsi que pour le processus de désertification. Il faut avancer avec les mesures agro-environnementales actuelles ayant comme objectif la conservation du sol, de la végetation arbustive et de la forêt de chênes, aussi bien que promovoir des usages agricoles et non agricoles nouveaux qui puissent contribuer pour la protection du sol et de l'eau comme ressources naturelles essentielles et pour la qualité de l'environnement et du paysage. Mots clés:

Dégradation du sol, érosion hydrique, bié, désertification, Alentejo.

\section{Abstract:}

Cereal cropping in general and wheat in particular was for along period, and still is, one of the most soil degrading agricultural activities in the Guadiana left river bank. Since early ages this area has been used for cereal cropping along a process of agricultural intensification and modernisation.

There, wheat is a evident degrading crop, that causes land degradation and depreciation of natural resources such as soil and water, dramatically increasing soil erosion and desertification. It is urgent to incentive the implementation of present EUCAP Agri-environmental measures, aiming at soil and water conservation, and in promoting new agricultural and non-agricultural land uses that consider the preservation and regeneration of natural shrub vegetation and Quercus forest, and the quality of the environment in a rural development approach.

Key words:

Soil degradation, hydric erosion, wheat, desertification, Alentejo.

\section{Introdução}

A cultura do trigo no Baixo Alentejo, e em particular na margem esquerda do rio Guadiana, tem sido apontada com uma das actividades antrópicas que mais têm contribuído para a degradação dos solos e, consequentemente, para o estado actual de desertificação desta área do País.

Apesar de o termo desertificação ser utilizado hoje em dia com frequência, e na maioria das vezes longe de corresponder ao seu verdadeiro significado, já em 1953 M. G. GUERREIRO alertava para o estado de degradação de vastas áreas do País, referindo:

\footnotetext{
* En colaboração con Jorge Manuel Mourão - Centro de Estudos de Geografia e Planeamento Regional - FCSH - Universidade Nova de Lisboa-roxo.univ@teleweb.pt - imourao@teleweb.pt
}

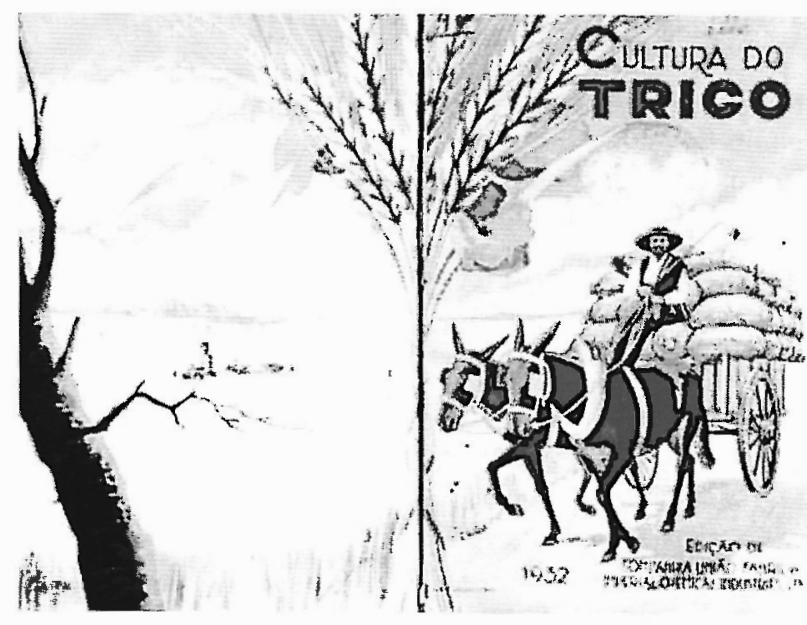

Capa de livro de divulgação da cultura do trigo - 1932 
“... Fomos longe demais, rompemos o equilíbrio natural, expusemos o solo aos ardores e mudanças bruscas do clima, degradámos a flora e o solo, criámos condições para a desertificação do território...".

OBaixo Alentejo interior corresponde, sem dúvida, a uma vasta área onde ao longo dos tempos a ocupação do território, o aumento da população e os diferentes usos do solo causaram um profundo desequilíbrio nos ecossistemas "naturais" ao diminuírem o seu potencial biológico e ao provocarem a degradação de recursos naturais vitais como são o solo e a água.

Durante vários séculos a actividade agrícola com base na produção de cereais, com particular destaque para o trigo, foi e continua a ser a principal cultura desta região, como são exemplos os concelhos de Mértola ou Serpa. No entanto, se o Homem tem uma enorme responsabilidade no estado de degradação em que se encontram os solos neste sector da bacia hidrográfica do rio Guadiana, as condições naturais são por si só favoráveis à actuação dos processos de erosão hídrica. Assim, o solo, sendo provavelmente o recurso mais importante da Biosfera, encontra-se permanentemente em risco, pondo em causa a estabilidade e o equilíbrio dos ecossistemas, bem como o bem-estar das populações rurais.

Foi possível equacionar e analisar, paralelamente à acção da erosão hídrica, a importância das práticas agrícolas na degradação dos solos a partir do momento em que Ernesto BAPTISTA D' ARAÚJO(1) instalou, no início da década de 60 , na Herdade de Vale Formoso (Concelho de Mértola), oCentro Experimental de Erosão de Vale Formoso (CEEVF). A possibilidade de obter valores referentes à perda de solo por acção das águas das chuvas e de assim analisar, de uma forma quantitativa, a actuação dos processos de erosão hídrica veio revelar a verdadeira dimensão do fenómeno de degradação dos solos por acção da cultura do trigo.

A instalação deste centro experimental justificouse pelo facto de ser urgente a necessidade de implementar medidas e técnicas de conservação de solo, uma vez que desde a década de 30 se reconhecia o avançado estado de degradação em que se encontravam os solos nesta área do País, o que foi denunciado com veemência por José M. MIRA GALVÃO ${ }^{(2)}$, quer em publicações do Ministério da Agricultura quer em jornais regionais e de âmbito nacional, como o Diário de Notícias - suplemento Notícias Agrícola.

\footnotetext{
(1) Engenheiro agrónomo da Direcção Geral de Hidráulica e Engenharia Agrícola.

(2) Engenheiro agrónomo Director do Posto Agrário de Beja - Chefe da XVIII Brigada Técnica durante as décadas de 30 e 40
}

Em virtude de se ter consciência de que a cultura dos cereais se tornava degradante, o programa experimental então delineado tinha por objectivo o estudo do comportamento do solo em relação a novas culturas e a diferentes técnicas de mobilização, tendo sempre por base de comparação a cultura do trigo. Neste sentido foram instaladas no CEEVF, dezasseis parcelas experimentais, idênticas às utilizadas por W. $\mathrm{H}$. WISCHMEIER (1958), para o desenvolvimento da Equação Universal de Perda de Solo, com cerca de 20 metros de comprimento e 8,33 metros de largura, o que corresponde a uma superfície rectangular de $166,6 \mathrm{~m}^{2} \mathrm{e}$ a aproximadamente $1 / 60$ de hectare.

A complexidade do fenómeno de degradação dos solos, pela interpenetração de factores humanos e naturais, faz com que seja essencial um bom conhecimento das características específicas de cada área, sendo por esta razão arriscada a generalização. Assim, a informação obtida no CEEVF permite avaliar o processo de erosão hídrica dos solos no que se refere a uma unidade pedológica específica e em condições climáticas e morfológicas particulares.

A verdade é que muitos autores tem escrito sobre a cultura de cereais e sua acção na degradação do solo, dando particular destaque às Campanhas do Trigo durante o regime do Estado Novo, mas este processo tem, nesta área do Baixo Alentejo, uma origem muito anterior.

Os factores demográficos, económicos, sociais e culturais, bem como as transformações impostas por medidas e políticas de âmbito nacional e internacional, com maior ou menor impacto sobre o território, têm sido os factores determinantes na pressão exercida sobre os recursos naturais, por si só já escassos nesta área marginal.

O risco de perda de fertilidade dos solos e consequente diminuição da biodiversidade continua a ser uma realidade, não só no Baixo Alentejo mas em vastas áreas de Portugal, sendo urgente actuar no sentido da sua mitigação e do combate ao fenómeno da desertificação.

\section{Aspectos socioeconómicos}

Na margem esquerda do rio Guadiana, em particular na área das "serras"(3) de Serpa e Mértola, foi possível, através da pesquisa histórica, detectar quais as fases que tinham provocado maiores transformações no

(3) Optou-se pela designação "serra", para simplificar, uma vez que a serra de Serpa e a serra de Mértola correspondem à mesma unidade de relevo. 
uso do solo. Identificaram-se quatro etapas decisivas, que têm como denominador comum a cultura dos cereais.

\section{Primeira Fase - A partir do século XVII}

A destruição da vegetação "natural" que cobria os terrenos "maninhos" deste sector da bacia do rio Guadiana e que correspondia, como referem vários autores, a matos densos, onde se denotava uma grande variedade florística, começa a ter lugar em virtude do aumento da população nesta área fronteiriça, originado pela fuga dos judeus que viviam em Espanha e que eram perseguidos pela Inquisição.

A pressão sobre os recursos naturais iniciava-se em função da necessidade de cultivar mais cereais, de melhorar as pastagens e obter mais madeira para combustível (lenha) e para a construção. As arroteias intensificaram-se e começou a assistir-se a partir dessa altura a uma utilização desregrada dos recursos que este território oferecia.

A cultura de cereais era então feita de forma itinerante, com base na queimada e na roça, à custa de uma fertilidade natural, tendo havido a necessidade da criação em Serpa de um Celeiro Comum - 1690, onde era guardada parte da produção com o fím de fazer face a crises de fome, causadas pelos maus anos agrícolas.

A verdade é que o arroteamento dos terrenos baldios tinha iniciado um processo de degradação de solos que não iria parar. Assim, já que em 1758 diferentes párocos alertam nos relatórios que constam das Memórias Paroquiais para a forma abusiva como se destruía a vegetação natural, como se cortavam os sobreiros e as azinheiras sem qualquer respeito pela Natureza.

Bem elucidativa desta situação é a opinião expressa pelo pároco de Corte de Pinto, que refere: “...Os privilégios que têm não só os moradores desta Aldeia mas também todos os moradores deste distrito de Cambas (...) é o de desfrutarem toda a Serra, assim do que nela semeam como frutos de árvores que são sobreiros (...) verdade que eles abusão de tal sorte deste privilégio que vão destruindo (...) que não só cortam todas as árvores que querem, mas ainda as queimam, contando o prejuízo do bem comum..." (in ROXO, 1994, p. 322).

\section{Segında Fase - Século XIX}

A abertura da Mina de S. Domingos (1859) no Concelho de Mértola vai provocar novamente um aumento significativo da população, tendência que se mantém durante o período áureo de laboração, que se verificou até 1874 . Freguesias como a de Corte de Pinto, com cerca de 588 habitantes em 1864 passou a 3638 habitantes em 1890. Como refere EREIO e COSTA (1991, p.142), a mina “...actuou como catalisadora de fluxos imigratórios significativos para uma região anteriormente inabitada...".

Novamente se assiste a um aumento das áreas arroteadas para a produção de cereais, ao mesmo

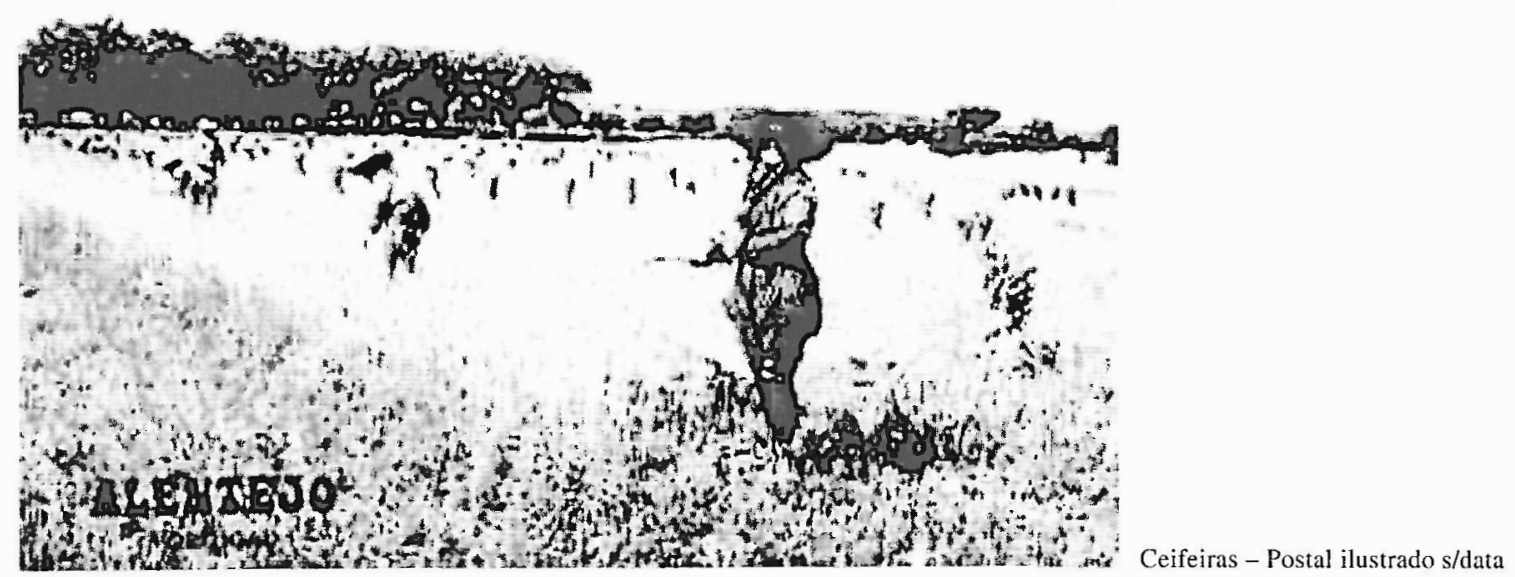




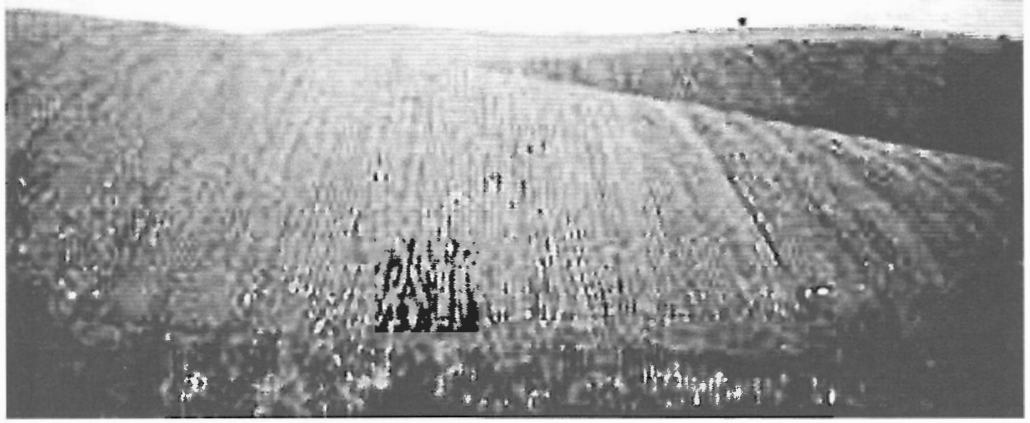

tempo que se verifica uma forte vaga de destruição da vegetação "natural" em função da necessidade de produção de carvão vegetal para a laboração da mina. À medida que a população ia utilizando com maior intensidade este território, iam sendo, ao mesmo tempo, provocadas maiores agressões ambientais. Acredita-se que as áreas mais transformadas seriam as localizadas mais perto das povoações.

Apesar da cultura de cereais ser então uma cultura itinerante, ocupava já em 1897 cerca de 5,3\% de um território com cerca de 50.000 hectares, como foi possível constatar através da Carta Agrícola e Florestal elaborada no final do século XIX, à escala 1: $50000^{(4)}$.

\section{Terceira Fase - Séc. XX}

A Lei Protectora de Cereais (Elvino de BRITO 1899), que estabelecia um preço fixo remunerador, suportado pelos consumidores finais, e não pelo Estado, e que apenas permitia a importação quando todo o trigo produzido tivesse sido escoado, incentivou a produção, tendo-se verificado um aumento significativo da área dedicada ao cultivo deste cereal.

Outro aspecto importante, associado ao anterior, foi o surgir de um sentimento de luta contra os incultos, bem ilustrado pelo título da notícia publicada pelo jornal "O Século", em 1906: «Portugal Inculto - Quase Metade do País Está por Cultivar - A Vergonha da Europa.»

(4) Foram analisadas as minutas de campo dos levantamentos efectuados referentes às folhas não publicadas da Carta Agrícola, para se avaliar a globalidade da área em estudo.
Este movimento pretendia a criação de uma lei que obrigasse à divisão dos terrenos baldios de maneira a incentivar o desenvolvimento agrícola do País. Dentro desta perspectiva, uma das áreas mais focadas pelo discurso político da época era a da "serras" de Serpa e de Mértola, não só pela sua dimensão mas pela ideia de que seriam terrenos muito férteis onde se poderiam cultivar várias culturas.

A realidade é que em 1906 o Baldio da "serra" de Serpa, cerca de 40.000 hectares, foi dividido em 5464 pequenas propriedades (glebas), de seis hectares cada. O mesmo aconteceria mais tarde ao Baldio da "serra" de Mértola, em 1926, em que aproximadamente 9660 hectares foram repartidos em 2610 glebas, tendo mais de $50 \%$, dimensões entre os dois e seis hectares. A pulverização do território que esta medida política causou iria ter consequências drásticas em termos de degradação dos recursos naturais.

Paralelamente, é implementada uma política de fixação da população em áreas mais despovoadas, trabalho desenvolvido pela Junta de Colonização Interna e que teve como resultado o estabelecimento de alguns núcleos populacionais, bem como a dinamização de outros, caso de Vale Mortos na "serra" de Serpa.

Ao mesmo tempo que havia necessidade de povoar as áreas interiores do País, menos atractivas e mais pobres, a política do Estado Novo tinha como objectivo prioritário o desenvolvimento agrícola, sobretudo no que dizia respeito à auto-suficiência em cereais, pelo que colocou em prática várias campanhas, conhecidas por Campanhas do Trigo. 
Os apelos à "Batalha da Produção Cerealífera" e ao "Regresso à Terra" passaram pela concepção e pelo funcionamento de uma enorme máquina de propaganda, que envolveu os sectores público e privado. Bons exemplos são as folhas de divulgação e os cartazes, onde se podiam ler frases como os "Quatro Mandamentos Cívicos - PRODUZIR, ECONOMIZAR, PRESERVAR E TER FE'" ou ainda os "10 Mandamentos do Cultivador", dos quais se transcrevme apenas dois "... $1^{\circ}$ - Amanha a tua terra com boas máquinas...; (...) $10^{\circ}$ - Não esqueças nunca que o trigo da nossa terra é a fronteira que melhor nos defende...".

Relevante foi também a realização de eventos de demonstração, como o caso do Comboio do Trigo, para divulgação de maquinaria agrícola e de produtos químicos, e a atribuição de prémios e diplomas aos melhores agricultores.

Todas estas iniciativas políticas tiveram sérias consequências na margem esquerda do rio Guadiana. A área de culturas arvenses de sequeiro, que era no final do século XIX cerca de 5.3\%, passou a ser em 1947 de $83,6 \%$.

Não é difícil imaginar qual seria a imagem deste território, onde tinha sido praticamente destruída toda a vegetação "natural" e predominava uma agricultura intensiva baseada numa rotação de alqueive-trigo-alqueive em que não era possível deixar a terra de pousio pois a dimensão das propriedades não permitia essa prática.
O solo foi, desta forma, exposto de um maneira grave à acção dos processos erosivos, com particular destaque para a actuação da erosão hídrica, em função das práticas culturais associadas ao cultivo do trigo (mobilizações, aplicação de herbicidas e adubos) e da fraca protecção dada por este cereal durante a sua fase de crescimento. De referir também que com a mecanização os trabalhos de alqueive e de sementeira se tornaram mais rápidos e eficazes mas muito mais nocivos para o solo.

\section{Quarta Fase - de Abril de 74 aos anos 90}

O aumento das áreas incultas por esgotamento e abandono da terra passou a ser uma realidade. A perda de fertilidade dos solos, bem como o seu avançadoestado de degradação, facilmente reconhecido pelo aparecimento da rocha-mãe à superfície e por um solo cada vez mais pedregoso, desencadeou movimentos migratórios que tiveram como consequência o en velhecimento da população, o despovoamento e o abandono dos campos.

A população envelhecida abandonou os "montes" que se encontravam dispersos pela "serra", por motivos de segurança e conforto (electricidade, água canalizada), tendo preferido instalar-se em pequenos núcleos populacionais, o que contribuiu para o crescimento destes, como é o caso de Vale do Poço. O estado e o número de "montes" em ruína são um bom indicador da perda de dinâmica desta área do Baixo Alentejo.

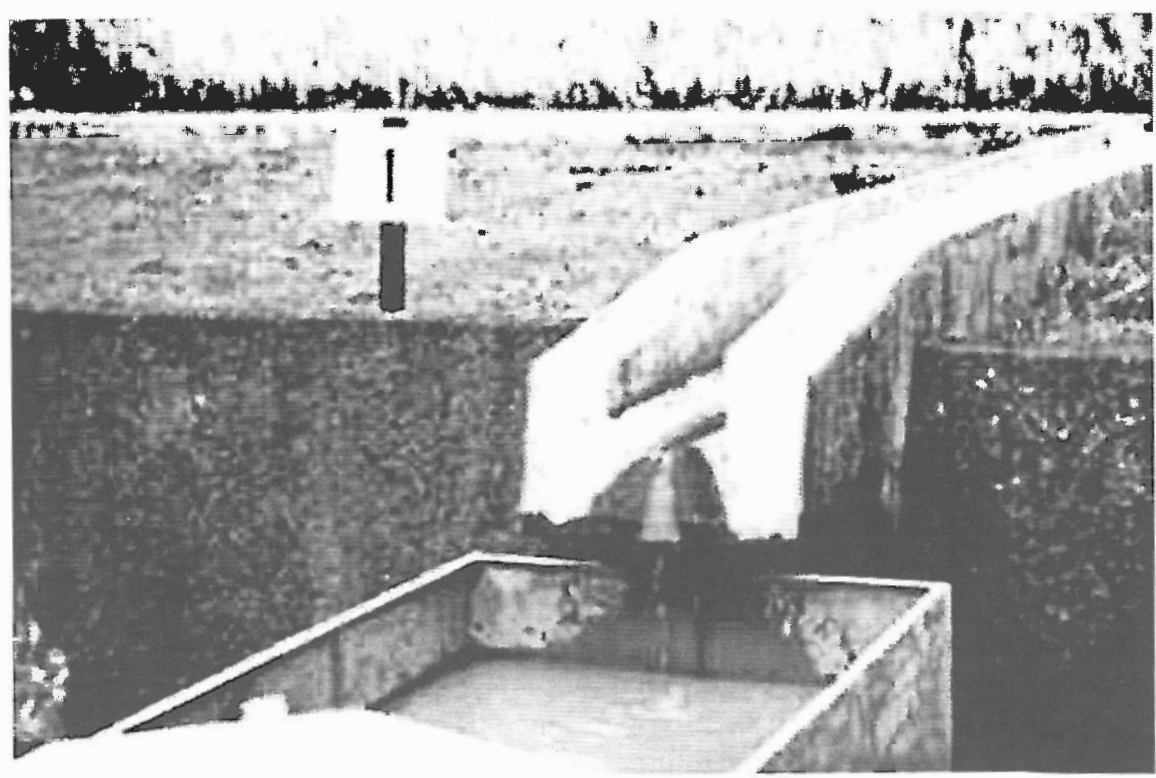

Parcela experimental (caleira e tanque), Centro Experimental de Erosão de Vale Formoso 
No entanto, o abandono da terra teve outro efeito, o do aumento da dimensão da propriedade (venda e compra de antigas glebas), que em termos ambientais se pode considerar positivo, uma vez que possibilita maiores pousios e uma exploração menos intensiva do recurso solo. Mas nem sempre tal se verificou, houve muitos casos em que o aumento da dimensão das propriedades se traduziu por um acréscimo no efectivo pecuário e consequentemente por uma utilização pouco racional das pastagens naturais, ou ainda pelo incremento da área de sequeiro.

A adesão à Comunidade Económica Europeia veio dar um novo incentivo à cultura dos cereais, cuja produção não deixou de ser subsidiada mas a nova conjuntura proporcionou um aumento do poder de aquisição de melhor maquinaria agrícola, em função das várias possibilidade de utilização de linhas de crédito, da existência de ajudas à produção e de indemnizações compensatórias.

A possibilidade de adquirir de uma forma mais fácil máquinas mais potentes, que permitiam efectuar mobilizações mais profundas e arrotear vastas áreas de forma eficaz e rápida, teve consequências graves em termos ambientais.

A política de subsídios, associada à irregularidade climática, tem sido responsável por uma enorme variabilidade anual da superfície cultivada com cereais. Pode mesmo afirmar-se que a área a ser semeada em cada ano agrícola está dependente da produção obtida no ano anterior (fortemente relacionada com as características do ano climático), dos montantes atribuídos à plantação de outras variedades (trigo rijo) e também da adesão à implementação de novas medidas de incentivo à reconversão do sistema cerealífero.

Apesar de ser já notória uma mudança no uso do solo em algumas áreas da "serra", em função da aplicação de medidas de apoio à florestação dos solos agrícolas, caso do Reg./CEE n. ${ }^{\circ} 2080$, a cultura cerealífera continua ainda a ocupar um espaço significativo neste sector da bacia do rio Guadiana e a causar sérios problemas de degradação dos solos.

\section{A degradação de solos por erosão hídrica}

Se por um lado a degradação dos solos é em grande parte da responsabilidade da actividade agrícola (cultura de cereais, sobrepastoreio), também o clima, o tipo de formas de relevo, a constituição geológica dos terrenos e a natureza dos solos tiveram influência na situação actual.
Neste contexto, a área da "serra" é um bom exemplo de um território onde a conjugação de factores naturais e antrópicos favorece a actuação eficaz dos processos e mecanismos que intervêm na erosão hídrica dos solos.

Todos os anos, na época de chuvas mais intensas, que ocorrem entre Novembro e Maio, é possível constatar pela cor barrenta dos cursos de água a enorme quantidade de sedimentos que transportam em suspensão, resultantes da lavagem superficial das vertentes efectuada pelas águas de escorrência.

A actuação dos processos de erosão hídrica na degradação dos solos que têm sido sujeitos à cultura do trigo nesta área da margem esquerda do Guadiana tem sido analisada através de estudos experimentais, efectuados no Centro Experimental de Erosão de Vale Formoso (CEEVF), instalado na serra de Mértola desde 1960.

Utilizando a informação recolhida em 18 parcelas experimentais (designam-se de talhões), idênticas às utilizadas por WISCHEMEIER, apresentando cada parcela experimental $20 \mathrm{~m}$ de comprimento e $8,33 \mathrm{~m}$ de largura, o que corresponde a cerca de $1 / 60$ do hectare, foi possível observar o tipo de coberto vegetal (percentagem de cobertura) e a maneira como é lavrado o solo, dois dos principais factores a ter em conta quando se pretende minimizar a acção das gotas da chuva no processo de erosão dos solos.

O facto de Ernesto BAPTISTA D'ARAÚJO ter delineado para o CEEVF um Programa Experimental de Conservação de Solo, que tinha como finalidade saber quais as técnicas de cultivo, rotações e afolhamento de culturas, que melhor conservariam o solo, tendo por base de comparação parcelas experimentais cultivadas com trigo permitiu analisar até que ponto esta cultura contribuiu de forma nefasta para a degradação dos solos.

Como se sabe, a cultura do trigo tem a particularidade de deixar o solo a nu e mobilizado durante um largo período aquando das sementeiras e a própria planta não proporciona uma boa protecção ao solo. Sendo assim, a acção erosiva das gotas da chuva é extremamente eficaz., como pode deduzir-se do gráfico (Figura 1) e dos valores de perda de solo que se apresentam.

Assim, na rotação Alqueive-Trigo verifica-se em média cerca de $48 \%$ do total de perda de solo na situação de alqueive, $31,5 \%$ durante a fase de crescimento e permanência do trigo e $20,5 \%$ na situação de restolho. A perda de solo em função da cultura do 
trigo correspondente, em média, a cerca de 2,5 Ton/ hectare/ano, tendo-se no entanto registado um valor máximo de 4 Ton/hectare no período de 1989/92.

De realçar que o valor máximo de perda de solo registado para o mesmo período em situação do solo a nu lavrado, segundo o maior declive (de cima a baixo), foi de 12 Ton/hectare.

Como pode depreender-se da Figura 1, existe uma grande variabilidade interanual nos valores de perda de solo, devido a estreita relação com as características pluviométricas de cada ano.

A realidade é que o tipo de clima que caracteriza esta área da margem esquerda do rio Guadiana favorece a acção da erosão hídrica por apresentar um regime pluviométrico muito irregular, podendo ocorrer anos muito secos, como foi o caso de 1980/81, com apenas $236 \mathrm{~mm}$, ou anos muito chuvosos, como foi o de 1989/90, em que se registaram $1041 \mathrm{~mm}$, tendo em conta que o valor da precipitação média anual é de cerca de $561 \mathrm{~mm}$. Outro aspecto relevante é o facto de as chuvas se concentrarem no final do Outono e Inverno, coincidindo deste modo com os trabalhos de mobilização do solo para as sementeiras do trigo.

A irregularidade das precipitações e a variação das temperaturas condicionam igualmente o estado de crescimento e desenvolvimento do trigo, que se traduz por maior ou menor protecção ao solo. A densidade da cultura e as características de cada planta estão em relação directa com a quantidade de solo a nu que fica directamente exposto aos agentes erosivos.
Contudo, outros aspectos físicos como o relevo, a litologia e o tipo de solo apresentam traços e propriedades que contribuem para uma maior eficácia da acção da erosão hídrica no processo de degradação dos solos. A morfologia caracteriza-se na área das "serras" de Serpa e de Mértola por uma sucessão de colinas, com vertentes declivosas e topos aplanados, com altitudes que variam entre os 200 e os 220 metros, através dos quais se pode reconstituir o nível da peneplanície.

A presença de rochas metamórficas, onde predominam os xistos vermelhos argilosos, com intercalações de filões de quartzo, datados do Devónico (Formação do Pulo do Lobo), sendo pouco susceptíveis à alteraçãa, resistem pouco à erosãolinear imprimida pelos cursos de água por serem praticamente impermeáveis, estando assim criadas as condições para o desenvolvimento de uma densa rede de drenagem, de padrão dendrítico e de regime torrencial.

Em função da litologia, os solos sãona generalidade pouco evoluídos, delgados e pedregosos $(10 \mathrm{a} 30 \mathrm{~cm})$, pobres em matéria orgânica, de estrutura fina (areias, limos e argilas), com fraca ou nula aptidão agrícola, sendo muito fácil romper o seu estado de equilíbrio.

\section{Considerações finais}

«É tão linda a nossa terra

Tanto por nós é amada

Que muito gosto dá ver

Quando está bem alqueivada»

Quadra popular
Talhões 1, 2, 10 e 11, Vale Formoso, 1961-1992

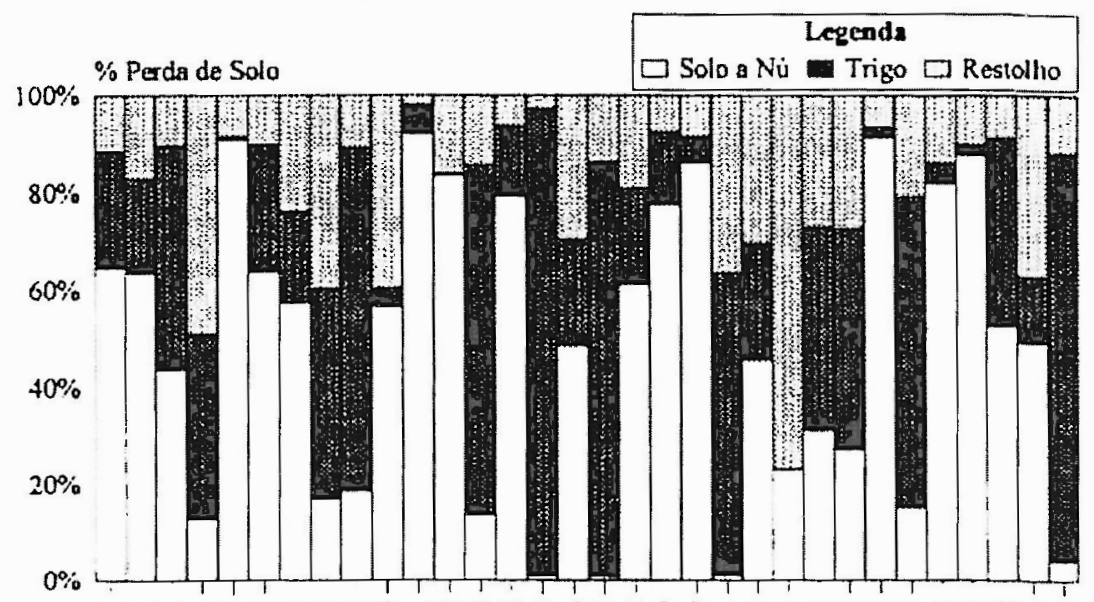

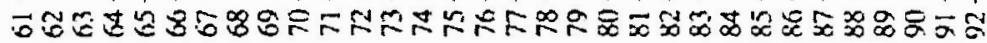

Fig. 1 - Perdas de soio anuais (\%) por tipo de cobertura de solo (Fonte - ROXO, 1994) 
Perante as condições naturais deste território, e tendo em conta o seu passado em termos de ocupação e uso do solo, pode facilmente entender-se porque corresponde a uma das áreas mais degradadas do País, onde o problema da desertificaçãoé uma realidade.

No entanto, apesar dos trabalhos de experimentação desenvolvidos por diversos investigadores na Herdade de Vale Formoso, quer em termos agrícolas ou no que se refere à erosão hídrica do solo, nunca foram postas em prática quaisquer medidas de conservação do solo.

Assistiu-se de forma passiva ao esgotamento dos solos, situação que era já frequentemente mencionada na década de 30 por ser então visível uma perda de produtividade agrícola que só era compensada com a utilização de produtos químicos em quantidades cada vez maiores, como resultado de várias acções e atitudes:

- Uso abusivo do recurso solo, que na sua origem é um solo pobre e sem aptidão agrícola;

- Utilização de máquinas mais potentes, que possibilitam a execução de lavouras mais profundas, que garantem maior rentabilidade e produtividade, bem como uma menor dependência das condições climáticas;

- Continuação da utilização de técnicas e práticas agrícolas profundamente enraizadas, como as mobilizações profundas no sentido docomprimento da vertente ou as rotações Alqueive/Cereal/Pousio/ /Cereal ou ainda Alqueive/Cereal, na cultura do trigo.

O risco de degradação dos solos por erosão hídrica continua a ser extremamente elevado em muitas áreas do País, com particular incidência nas áreas agrícolas, pelo que urge incentivar a aplicação das Medidas Agro-Ambientais e promover a divulgação de informação junto dos agricultores e proprietários no sentido de alertar para a necessidade de preservar e conservar os recursos naturais, com a finalidade de garantir um desenvolvimento sustentável das áreas rurais marginais, como é o caso da margem esquerda do rio Guadiana.

\section{Bibliografia}

AFFREIXO, J. M. Graça (1993) - Memória Histórico - Económica do Concello de Serpa, Serpa, Arquivo Histórico Municipal, Câmara Municipal de Serpa, $1^{a}$ ed. 1884.

BARROS, Aguiar (1989) - "Aptidão de terras de solos esqueléticos e delgados de xistoem Portugal". Dedon, Sociedade Portuguesa de Ciência do Solo, Lisboa, 7, pp. 3-61.
BARROS, Henrique de; CASCAIS, Manuel (1956) - A cultura Arvense no concelho de Serpa: Monografia Técnica Económica, Lisboa, FNPT.

BENTO, J. I. F. (1918) - Do Baldio da Serra Grande de Serpa - breve esboço de economia agrícola,s.l.

BOARDMAN, J. et al (1990) - Soil erosion on agricultural land, Chichester, Jonh Wiley \& Sons, 687 p.

CABRAL, M. Villaverde (1974) - Materiais para a questão agrária em Portugal, séculos XIX e XX, Porto, INOVA, 572 p.

CASTRO, Luís de (1893) - A produção e a cultura do trigo em Portugal, Lisboa, Bib. do Pot. Agrícola.

COSTA, Pdre António C. da (1708) - Chorografia Portugueza, Lisboa, 477 p.

DICCIONÁRIO GEOGRÁFICO (1758) - Memórias Paroquiais, 43 vol.

EREIO, Mário J. S. R. T.; COSTA Serafim M. B. (1991) - Mina de S. Domingos: OAlentejo sem Esperança?(Tese de Licenciatura em Geografia e Planeamento Regional, nãopublicado), Lisboa, FCSH-UNL.

Federação Nacional dos Produtores de Trigo (1956) - A cultura Arvense no concelho de Beja: Monografia Técnica Económica, Lisboa.

Ministério da Agricultura (1939) - Reconhecimento dos Baldios do Continente, Vol. I, Lisboa, Junta de Colonização Interna, pp. 1-178.

MINISTÉRIO DA ECONOMIA (1957)-O Campo Experimental de Vale Formoso na Serra de Mértola, Beja, Direcção Geral dos Serviços Agrícolas, Brigada Técnica da XIV Região Agrícola.

MIRA GALVÃO, J. M. (1949) - "Algumas considerações sobre a Mobilização do Solo", Agros, Ano XXXII, N. . 2-3, Beja, pp. 1-16.

PAIS, José Machado; et al (1976) - "Elementos para a História do Fascismo nos Campos: a «Campanha do Trigo»: 1928-1938", Análise Social, Vol. XII, N. ${ }^{\circ} .46$, Lisboa, pp. 321-389, 400-473.

ROSA, Carlos Alberto (1982) - "Estudo comparativo em talhões experimentais de erosão de cereais, forragens e pastagens Vale Formoso", Pastagens e Forragens, Vol. 3, s.1., pp. 7-20.

ROXO, Maria J. e CASIMIRO, Pedro C. (1993) - "A monocultura cerealífera no Baixo Alentejo Interior e o processo de desertificação", Seminario sobre la desertificacion y la utilizacion del suelo en la cuenca Mediterranea, Almeria, Espanha.

ROXO, Maria J. (1994) - A Acção Antrópica no Processo de Degradação de Solos-a Serrade Serpa Mértola, Dissertação de Doutoramento, DGPR - FCSH - Universidade Nova de Lisboa, Lisboa, 387 p.

WISCHMEIER, W.H.: SMITH, D. D. et al (1958) - "Evaluation of factors in the soil loss equation", Agricultural Engineering, $\mathrm{N}^{\circ} 39$. 